\title{
A Comparative Study of Arch Widths of Bangladeshi Subject with Normal Occlusion and Class II Division 1 Malocclusion
}

\author{
Islam MM1 BDS, FCPS and Hossain MZ ${ }^{2}$ BDS, PhD
}

\begin{abstract}
Aim: To evaluate possible differences of the upper and lower dental arches width among youths with Class I,normal occlusion and Class II, division 1 malocclusion.

Materials and Methods: The evaluation was conducted on 100 pairs of dental casts of Bangladeshi youths with permanent dentition, 50 with Class I, normal occlusion (22 males and 28 females) at the mean age of $19 \pm 3$ years and 50 with Class II, division 1, malocclusion (18 males and 32 females ) at the mean age of $20 \pm 4$ years. The group with Class II malocclusion was divided into two categories: Class II without dental crowding and Class II with dental crowding. A comparison was made between the intercanine inter first premolar and intermolar widths of both dental arches.
\end{abstract}

Results: Subjects with Class II, division, 1 malocclusion when compared with Class I normal occlusion presented

(a) in the upper dental arch, smaller intermolar, interpremolar and intercanine width.

(b) in the lower dental arch, smaller intermolar width.

Conclusion: From the results it may be concluded that the subject with Class II, division 1, malocclusion had presented a trend for posterior transverse deficiency of dental arches mainly in female group with crowding. (Bangladesh Journal of Orthodontics and Dentofacial Orthopedics, Vol. 2, No. 2, April 2012, p 18-23).

\section{INTRODUCTION}

Class II malocclusion is reported as the most frequently seen skeletal disharmony in orthodontic population. Cephalometrically it is characterized by a variety of skeletal pattern. Class II, division 1 malocclusion may be related with mandibular retrognathia ${ }^{1,2}$ maxillary prognathism or a combination of both ${ }^{3}$ whereas the cranial base may also be involved. ${ }^{3}$ In an effort to describe the typical class II, division 1 malocclusion the following are the characteristics. ${ }^{4}$

In frontal view of face is usually oval (Mesocephalic to Dolicocephalic). A convex profile with posterior divergent face. Incompetent or stretched upper lip due to proclined upper incisors. Lower lip is everted and there is lack of lip seal. Intra orally Class II molar relationship, proclined upper incisors and an increased overjet. An exaggerated curve of spee of mandible. Upper arch is usually narrow, $\mathrm{V}$ shaped. There is deep bite which is usually traumatic in nature.Other features may be an open bite,cross bite,crowding etc.

Heredity seems to play an important role in the development of this type of malocclusion. ${ }^{5-9}$ According to Bassigny (1983), ${ }^{10}$ the etiology of class II, division 1 malocclusion in dolicocephalic people may be hereditary or functional (activity of the tongue, activity of facial muscles or, head posture). On the other hand, in brachyfacial people, functional factors (lower lip or, tongue activity) do not seem to be important. Local environmental factors (eg premature exfoliation of primary teeth) seem to affect a class II malocclusion of dental rather than of skeletal etiology. ${ }^{7,8,11,12}$
Class II malocclusion problems are often combined with jaw and dental arch discrepancies on the sagital as well as on the transverse or vertical planes. ${ }^{13,14}$ Orthodontic treatment of these malocclusions and especially non extraction treatment plans, often include expansion of the upper dental arch. Dental arch dimensions change during treatment as well as during the retention phase. Nevertheless, research studies about dental arch dimensions during the active growth period are few and concern only certain parameters. Papageorgiou et al (1998) ${ }^{15}$ studied dental dimensions in people with Class II division 2 malocclusion. Some authors made a comparative study on arch widths between Class II Division 2 and Class II division 1 malocclusion. Concerning Class II division1 malocclusion some studies are available. A very recent study conducted over white Brazilians to compare the arch widths with normal occlusion and Class II division 1 malocclusion. Staley et al (1985) as well as Buschang et al $(1992)^{16}$ examined dental arch differences in adults. Toutountzakis (1989) examined upper intermolar widths in children, Frohlich $(1961 ; 1962)$ states the upper and lower intermolar and intercanine widths, whereas Ingervall and Lennartsson (1972) examined intermolar widths and length of both dental arches. Baccetti et al (1997) studied the changes and widths discrepancies of both dental arches at the region of primary and permanent molars on dental casts. Bishara et al (1996) ${ }^{17}$ studied length changes and arch discrepancies of both dental arches in Class II division 1 malocclusion.

In Bangladesh, no such studies been made to evaluate them in our context. Our efforts were confined to isolated case management and study of prevalences. A precision in determining possible differences in the dental arches widths of Bangladeshi people between Class I normal occlusion and class II division 1 mal- 
occlusion may be an important aid in further understanding of dentoalveolar characteristics of these conditions as well as improving their management.

\section{MATERIALS AND METHODS}

Study design: Cross sectional study

Place of study: Department of Orthodontics \& Dentofacial Orthopedics of Dhaka Dental College \& Hospital, Dhaka

Period of study: July :2006 to July 2009 (3 years)

\section{Sample selection:}

In this study 100 pairs of study models were selected from patients and students of the Orthodontics \& Dentofacial Orthopedics Department of Dhaka Dental College \& Hospital and were divided into two groups. The first group consisted of 50 pairs of study models ( 22 males and 28 females ) with permanent dentition and diagnosed as class I normal occlusion. The second group includes another 50 pairs of dental casts (18 males and 32 females) with permanent dentition and diagnosed as Class II division 1 malocclusion. This group of malocclusion was again divided into two categories, Class II division 1 malocclusion with crowding and classII division1 malocclusion without crowding.

\section{SELECTION CRITERIA}

Inclusion criteria: For class I, Normal Occlusion (50 subjects)

1. Bilateral class I molar relationship

2. Normal overjet and ovetbite, spacing and crowding less than $2 \mathrm{~mm}$.

3. Class I soft tissue profile

4. No missing teeth except wisdom teeth.

5. Absence of posterior cross bite even limited to a single tooth.

Inclusion criteria: For Class II division 1 malocclusion (50 subjects)

1. Bilateral Class II molar relationship.

2. Protrusive maxillary incisiors, overjet more than $5 \mathrm{~mm}$.

3. Convex soft tissue profile.

4. No missing teeth except wisdom teeth.

5. Absence of posterior crossbite even limited to a single tooth.

6. No history of previous orthodontic treatment.

Exclusion criteria :

1. Posterior crossbite

2. Missing teeth other than wisdom teeth.

3. Age below 13 years.

4. History of previous orthodontic treatment.

\section{STUDY PROCEDURE}

Each of the subjects was selected in respect of inclusion and exclusion criteria. A data collection sheet with necessary measurements for each subject was filled.

\section{MEASUREMENTS}

The proposed study would be conducted on maxillary and mandiular dental cast of 100 Bangladeshi subjects of both sexes, 50 of them were Class I normal occlusion group and the rest 50 subjects were Class II division 1 malocclusion group. The malocclusion group was divided into two categories, Class II with crowding and Class II without crowding. Comparison made on intercanine interfirst premolar and intermolar widths of both dental arches.

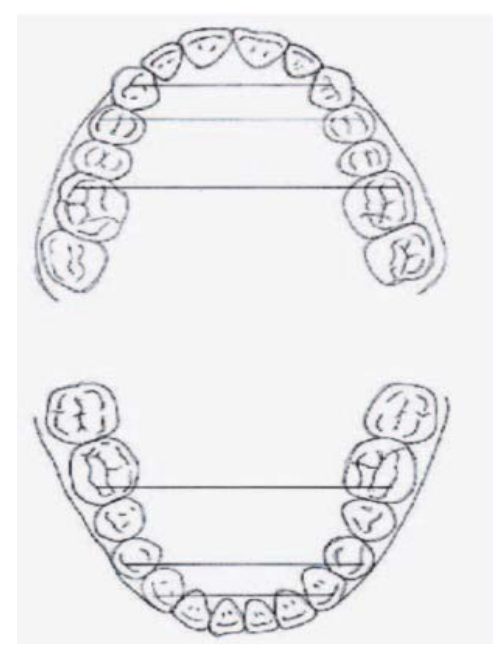

Fig-1 shows intercanine, interfirst premolar and intermolar widths of both Maxillary and Mandibular arches.

\section{Maxillary masurement}

Maxillary intercanine width- Distance between the cusp tips of right and left maxillary permanent canines.

Maxillary inter premolar width- Distance between the buccal cusp tips of right and left maxillary permanent first premolar.

Maxillary intermolar width- Distance between the mesiobuccal cusp tips of right and left maxillary permanent first molar.

\section{Mandibular measurements}

Mandibular intercanine width- Distance between the cusp tips of right and left mandibular permanent canines.

Mandibular inter premolar width- Distance between the buccal cusp tips of right and left mandibular permanent first pre- 
molars.

Mandibular intermolar width- Distance between the mesiobuccal cusp tips of right and left mandibular permanent first molars.

\section{DATA COLLECTION AND PROCESSING:}

Dental casts measurement was perfomed by a digital dial caliper to the nearest $0.01 \mathrm{~mm}$. All measurements of all subjects was carried out again two weeks later by an another operator to evaluate measurements error. Almost all the measurements were same measured by two operators, where differed, average was taken. After collection of data, the obtained data was checked, verified $\&$ edited. These were entered in a personal computer using the SPSS ( statistical package for social science) software. Entered data were cleaned, edited and appropriate statistical tests were done depending on the distribution of data.

Data analysis:

All datas were analyzed through standard statistical methods by using SPSS software.

\section{RESULTS}

This study was a cross sectional study conducted among the dental casts of 100 patients and students of department of Orthodontics and Dentofacial Orthopedics, Dhaka Dental College and Hospital. Both male and female were included. The occlusion of these subjects was Class I normal occlusion and Class II division1 malocclusion. The malocclusion group was again subdivided into crowding and without crowding group. The statistical tests to be used for analysis of data were t- test. In this analytical test the level of significance $p$ value $<0.05$ was considered significant.

Table-1 Mean age of study patients:

\begin{tabular}{llll}
\hline Type of occlusion & $\begin{array}{l}\text { Mean }( \pm \mathrm{SD}) \\
\text { years }\end{array}$ & $\begin{array}{l}\text { Minimum } \\
\text { years }\end{array}$ & $\begin{array}{l}\text { Maximum } \\
\text { years }\end{array}$ \\
\hline $\begin{array}{l}\text { Class I Normal } \\
\text { occlusion }\end{array}$ & $19.36( \pm 3.16)$ & 15 & 29 \\
$\begin{array}{l}\text { Class II div1 } \\
\text { Malocclusion }\end{array}$ & $19.64( \pm 3.64)$ & 14 & 28 \\
\hline
\end{tabular}

Table 2: Comparison of maxillary measurements between Class I normal occlusion and Class II div1 malocclusion.

\begin{tabular}{llll}
\hline Total $(\mathrm{n}=100)$ & $\begin{array}{l}\text { Class-I } \\
(\mathrm{n}=50)\end{array}$ & $\begin{array}{l}\text { Class-II div-1 } \\
(\mathrm{n}=50)\end{array}$ & \\
$\begin{array}{l}\text { Different arch } \\
\text { width }\end{array}$ & Mean $( \pm$ SD) mm & Mean $( \pm$ SD) mm & P value \\
\hline Intercanine & $34.88( \pm 1.84)$ & $33.57( \pm 3.12)$ & 0.01 \\
Interpremolar & $42.84( \pm 4.96)$ & $40.12( \pm 3.10)$ & 0.001 \\
Intermolar & $51.81( \pm 3.76)$ & $49.29( \pm 3.14)$ & 0.001
\end{tabular}

Level of $\mathrm{p}$ value significant $=<0.05$.
Table 2 shows maxillary intercanine, interpremolar and intermolar width differences between Class I normal occlusion and Class II division 1 malocclusion were statistically significant.

Table-3: Comparison of mandibular measurements between Class I normal occlusion and Class II div 1 malocclusion.

\begin{tabular}{|c|c|c|c|}
\hline Total $(n=100)$ & $\begin{array}{l}\text { Class-I } \\
(\mathrm{n}=50)\end{array}$ & $\begin{array}{l}\text { Class-II div-1 } \\
(\mathrm{n}=50)\end{array}$ & \\
\hline $\begin{array}{l}\text { Different arch } \\
\text { width }\end{array}$ & Mean $( \pm \mathrm{SD}) \mathrm{mm}$ & Mean $( \pm \mathrm{SD}) \mathrm{mm}$ & $P$ value \\
\hline Intercanine & $25.91( \pm 1.87)$ & $25.58( \pm 2.38)$ & 0.44 \\
\hline Interpremolar & $34.01( \pm 2.24)$ & $33.33( \pm 2.71)$ & 0.17 \\
\hline Intermolar & $44.71( \pm 2.76)$ & $42.71( \pm 2.94)$ & 0.001 \\
\hline
\end{tabular}

Table 3 shows only mandibular intermolar width differences were statistically significant between two groups. $p$ value was 0.001 .

Table-4: Comparison of maxillary measurements between Class I normal occlusion and Class II div 1 malocclusion among males

\begin{tabular}{|c|c|c|c|}
\hline Total $(n=40)$ & $\begin{array}{l}\text { Class-I } \\
(\mathrm{n}=22)\end{array}$ & $\begin{array}{l}\text { Class-II div-1 } \\
(\mathrm{n}=18)\end{array}$ & \\
\hline $\begin{array}{l}\text { Different arch } \\
\text { width }\end{array}$ & Mean $( \pm \mathrm{SD}) \mathrm{mm}$ & Mean $( \pm \mathrm{SD}) \mathrm{mm}$ & $P$ value \\
\hline Intercanine & $35.33( \pm 2.04)$ & $34.40( \pm 3.43)$ & 0.29 \\
\hline Interpremolar & $43.23( \pm 2.88)$ & $41.67( \pm 3.26)$ & 0.11 \\
\hline Intermolar & $52.57( \pm 4.47)$ & $50.99( \pm 2.99)$ & 0.19 \\
\hline
\end{tabular}

Table 4 shows maxillary intercanine, interpremolar and intermolar width differences between Class I, normal occlusion and Class II, division1, malocclusion were not statistically significant in male group.

Table-5: Comparison of mandibular measurements between Class I normal occlusion and Class II div 1 malocclusion among males.

\begin{tabular}{|c|c|c|c|}
\hline Total $(n=40)$ & $\begin{array}{l}\text { Class-I } \\
(\mathrm{n}=22)\end{array}$ & $\begin{array}{l}\text { Class-II div-1 } \\
(\mathrm{n}=18)\end{array}$ & \\
\hline $\begin{array}{l}\text { Different arch } \\
\text { width }\end{array}$ & Mean $( \pm \mathrm{SD}) \mathrm{mm}$ & Mean $( \pm \mathrm{SD}) \mathrm{mm}$ & $P$ value \\
\hline Intercanine & $25.98( \pm 2.07)$ & $25.92( \pm 3.11)$ & 0.94 \\
\hline Interpremolar & $34.96( \pm 2.22)$ & $34.86( \pm 2.89)$ & 0.90 \\
\hline Intermolar & $45.41( \pm 2.68)$ & $44.31( \pm 2.23)$ & 0.17 \\
\hline
\end{tabular}


Table 5 shows mandibular intercanine, interpremolar and intermolar width differences between Class I normal occlusion and Class II division 1 malocclusion were not statistically significant in male group.

Table-6: Comparison of maxillary measurements between Class I normal occlusion and Class II divi 1 malocclusion among females.

\begin{tabular}{llll}
\hline Total $(\mathrm{n}=60)$ & $\begin{array}{l}\text { Class-I } \\
(\mathrm{n}=28)\end{array}$ & $\begin{array}{l}\text { Class-II div-1 } \\
(\mathrm{n}=32)\end{array}$ & \\
$\begin{array}{l}\text { Different arch } \\
\text { width }\end{array}$ & Mean $( \pm$ SD) mm & Mean $( \pm$ SD $) \mathrm{mm}$ & P value \\
\hline Intercanine & $34.53( \pm 1.62)$ & $33.09( \pm 2.89)$ & 0.02 \\
Interpremolar & $42.54( \pm 6.16)$ & $39.25( \pm 2.68)$ & 0.01 \\
Intermolar & $51.22( \pm 3.04)$ & $48.34( \pm 3.03)$ & 0.001 \\
\hline
\end{tabular}

Level of $\mathrm{p}$ value significant $=<0.05$.

Table 6 shows maxillary intercanine, interpremolar and intermolar width differences between Class I, normal occlusion and Class II, divivision 1,malocclusion were statistically significant in female groups.
Table-7: Comparison of mandibular measurements between Class I normal occlusion and Class II div 1 malocclusion among females.

\begin{tabular}{llll}
\hline Total $(\mathrm{n}=60)$ & $\begin{array}{l}\text { Class-I } \\
(\mathrm{n}=28)\end{array}$ & $\begin{array}{l}\text { Class-II div-1 } \\
(\mathrm{n}=32)\end{array}$ & \\
$\begin{array}{l}\text { Different arch } \\
\text { width }\end{array}$ & Mean $( \pm \mathrm{SD}) \mathrm{mm}$ & Mean $( \pm \mathrm{SD}) \mathrm{mm}$ & P value \\
\hline Intercanine & $25.86( \pm 1.73)$ & $25.38( \pm 1.89)$ & 0.32 \\
Interpremolar & $33.27( \pm 1.99)$ & $32.47( \pm 2.21)$ & 0.14 \\
Intermolar & $44.15( \pm 2.75)$ & $41.81( \pm 2.94)$ & 0.002 \\
\hline
\end{tabular}

Level of $\mathrm{p}$ value significant $=<0.05$.

Table 7 shows only mandibular intermolar widths differences were statistically significant between class I normal occlusion and Class II division1 malocclusion in female groups. $\mathrm{p}$ value was 0.002 .

Table 8: Comparison of arch width measurements between Class I, normal occlusion and Class II, division1, malocclusion with crowding among sexes.

\begin{tabular}{|c|c|c|c|c|c|c|}
\hline \multirow{3}{*}{ Different arch width } & \multicolumn{3}{|c|}{ Male (28) } & \multicolumn{3}{|c|}{ Female (39) } \\
\hline & $\begin{array}{l}\text { Class-I } \\
(\mathrm{n}=22)\end{array}$ & $\begin{array}{l}\text { Class-II with } \\
\text { Crowding } \\
(\mathrm{n}=6)\end{array}$ & $\mathrm{P}$ value & $\begin{array}{l}\text { Class-I } \\
(\mathrm{n}=28)\end{array}$ & $\begin{array}{l}\text { Class-II with } \\
\text { Crowding } \\
(\mathrm{n}=11)\end{array}$ & $\mathrm{P}$ value \\
\hline & Mean $( \pm \mathrm{SD}) \mathrm{mm}$ & Mean $( \pm \mathrm{SD}) \mathrm{mm}$ & & Mean $( \pm \mathrm{SD}) \mathrm{mm}$ & Mean $( \pm \mathrm{SD}) \mathrm{mm}$ & \\
\hline Maxillary intercanine width & $35.33( \pm 2.04)$ & $32.75( \pm 3.21)$ & 0.02 & $34.53( \pm 1.62)$ & $31.47( \pm 3.25)$ & 0.00 \\
\hline Maxillary interpremolar width & $43.23( \pm 2.88)$ & $39.51( \pm 2.78)$ & 0.009 & $42.54( \pm 6.16)$ & $38.09( \pm 3.38)$ & 0.03 \\
\hline Maxillary intermolar width & $52.57( \pm 4.47)$ & $49.71( \pm 2.21)$ & 0.04 & $51.22( \pm 3.04)$ & $47.76( \pm 4.28)$ & 0.02 \\
\hline Mandibular intercanine width & $25.98( \pm 2.07)$ & $25.16( \pm 4.50)$ & 0.52 & $25.86( \pm 1.73)$ & $25.17( \pm 2.37)$ & 0.32 \\
\hline Mandibular interpremolar width & $34.96( \pm 2.22)$ & $36.41( \pm 2.62)$ & 0.18 & $33.27( \pm 1.99)$ & $31.77( \pm 2.54)$ & 0.05 \\
\hline Mandibular intermolar width & $45.41( \pm 2.68)$ & $43.88( \pm 2.01)$ & 0.20 & $44.15( \pm 2.75)$ & $40.94( \pm 4.19)$ & 0.03 \\
\hline
\end{tabular}

Level of $\mathrm{p}$ value significant $=<0.05$.

Table 8 shows in male maxillary intercanine, interpremolar and intermolar width differences between Class I, normal occlusion and Class II, division1, malocclusion with Crowding were statistically significant. Mandibular intercanine, interpremolar and intermolar width differences between the groups were not statistically significant.

In female maxillary intercanine, interpremolar and intermolar width differences between Class I normal occlusion and Class II division 1 malocclusion with Crowding were statistically significant. Mandibular interpremolar and intermolar width differences between the groups were statistically significant. Mandibular intercanine width differences were not statistically significant. 
Table -9: Comparison of arch width measurements between Class I normal occlusion and Class II division1 malocclusion without crowding among sexes.

\begin{tabular}{|c|c|c|c|c|c|c|}
\hline \multirow{3}{*}{ Different arch width } & \multicolumn{3}{|c|}{ Male (34) } & \multicolumn{3}{|c|}{ Female (49) } \\
\hline & $\begin{array}{l}\text { Class-I } \\
(n=22)\end{array}$ & $\begin{array}{l}\text { Class-II with } \\
\text { Crowding } \\
(\mathrm{n}=12)\end{array}$ & $\mathrm{P}$ value & $\begin{array}{l}\text { Class-I } \\
(n=28)\end{array}$ & $\begin{array}{l}\text { Class-II with } \\
\text { Crowding } \\
(\mathrm{n}=21)\end{array}$ & $\mathrm{P}$ value \\
\hline & Mean $( \pm$ SD $) \mathrm{mm}$ & Mean $( \pm$ SD $) m m$ & & Mean $( \pm \mathrm{SD}) \mathrm{mm}$ & Mean $( \pm$ SD $) \mathrm{mm}$ & \\
\hline Maxillary intercanine width & $35.33( \pm 2.04)$ & $35.23( \pm 3.35)$ & 0.91 & $34.53( \pm 1.62)$ & $33.95( \pm 2.33)$ & 0.33 \\
\hline Maxillary interpremolar width & $43.23( \pm 2.88)$ & $42.75( \pm 3.02)$ & 0.65 & $42.54( \pm 6.16)$ & $39.86( \pm 2.08)$ & 0.03 \\
\hline Maxillary intermolar width & $52.57( \pm 4.47)$ & $51.62( \pm 2.66)$ & 0.50 & $51.22( \pm 3.04)$ & $48.65( \pm 2.18)$ & 0.002 \\
\hline Mandibular intercanine width & $25.98( \pm 2.07)$ & $26.31( \pm 2.30)$ & 0.67 & $25.86( \pm 1.73)$ & $25.50( \pm 1.64)$ & 0.46 \\
\hline Mandibular interpremolar width & $34.96( \pm 2.22)$ & $34.09( \pm 2.80)$ & 0.32 & $33.27( \pm 1.99)$ & $32.83( \pm 1.99)$ & 0.45 \\
\hline Mandibular intermolar width & $45.41( \pm 2.68)$ & $44.53( \pm 2.40)$ & 0.34 & $44.15( \pm 2.75)$ & $42.27( \pm 1.99)$ & 0.001 \\
\hline
\end{tabular}

Level of $\mathrm{p}$ value significant $=<0.05$.

Table 9 shows in male both maxillary and mandibular intercanine, interpremolar and intermolar width differences between the groups were not statistically significant. In female maxillary interpremolar, intermolar width differences between the groups were statistically significants. Only Mandibular intermolar width differences between the groups were statistically significant.

\section{DISCUSSION}

Authors investigating dental arch widths in different populations reported that in girls, little or no change of arch widths occurred in molar and canine region after 13 years of age. For this reason minimum age of the subjects participating in this study was 13 years. In our study to compare arch widths, we slected subjects without posterior crossbite, even in a single tooth. This will ensure accurate measurements of arch widths and will not affect the result. In addition to measurements in canine and molar region, arch widths between premolar teeth were also calculated.

The results of this study show that subjects with Class II division1 malocclusion present significant arch widths differences compared to subjects with Class I normal occlusion which support the hypothesis of this study. Statistically significant differences were smaller intercanine, interpremolar and intermolar widths In the upper dental arch and smaller intermolar widths in the lower dental arch.

Our result corroborates with the result of Ahmed N, Akhter F, Rahman MM. ${ }^{18-20} \mathrm{He}$ compared arch widths of 36 Class I normal occlusion subjects (19 males and 17 females) with 39 Class II division 1 subjects (20 males and 19 females) and reported that subjects with Class I normal occlusion had larger maxillary intercanine widths than the malocclusion subjects but no differences were found in mandibular intercanine widths. He also reported that subjects with Class I normal occlusion had larger maxillary intermolar widths. This study supports our result.

Our results differs from that of the results of Bishara et al and Frohlich. ${ }^{13}$

Bishara et al compared dental arch widths differences of 37 Class II division1 malocclusion subjects (15 males and 22 females) with 55 Class I normal occlusion subjects (28 males and
Frohlich found no difference in intermolar widths between Class I normal and Class II subjects.

Above differences of results may be explained by several factors such as,gender dimorphism, ethnic and racial differences,sample selection or size and age of subjects.

Both male and female were included in our study. Further the malocclusion groups were divided into two categories : Class II with crowding and Class II without crowding.

In male no statiscally significant differences were found between the groups. This may be due to small sample size.

In females maxillary intercanine, interpremolar, intermolar and mandibular intermolar widths differences were statistically significant.

When comparison was done between arch widths of Class II, division1 with crowding and Class I normal occlusion both male and female shows maxillary intercanine interpremolar and intermolar widths differences to be significant. Only mandibular intermolar widths differences in case of female was statistically significant.

When comparison was done between arch widths of Class II division1 without crowding and Class I normal occlusion male shows no significant arch widths differences. Female shows maxillary interpremolar, intermolar and mandibular intermolar widths differences to be statistically significant.

After discussing the results of this study it may be concluded that the subjects with Class II division1 malocclusion presented arch widths defficiency especially in female group with crowding.

A very recent study similar to our study over white Brazilian titled "A comparative study of arch widths of white Brazilian with Class I normal occlusion and Class II division1 malocclusion" 
(Roberto, Rajman, Martins, Decio Rodrigues, Scavone jr, Helio et al), July/August 2006, also concluded same to this study.

Determining possible widths differences on the dental arches between subjects with Class II division 1 malocclusion and subjects with Class I normal occlusion may be an important information in further understanding dental and dentoalveolar characteristics of these conditions. This information may have some impact on selection of treatment planning to malocclusion.

\section{CONCLUSION}

According to the results of this study subjects with Class II division1 malocclusion presented significant arch widths differences compared to subjects with Class I Normal occlusion.Statistically significant differences were smaller intercanine, interpremolar and intermolar width In the upper dental arch and smaller intermolar width In the lower dental arch.

Generally, the subjects with Class II division1 malocclusion have presented tendency of posterior arch width deficiency especially female group with crowding.

From the results It may be concluded that patients with Class II division 1 malocclusion present narrower dental arches (except for the lower anterior segment).

These characteristics could significantly affect treatment of patients with Class II division1 malocclusion and emphasis should be given in diagnosis and treatment planning as well as treatment mechanism.

\section{RECOMMENDATION}

As the size of the sample of this study was very small so recommendation is put forward for future researcher to do additional depth research consisting of large sample group for the greater acceptability of the study.

\section{REFERENCES}

1. Bishara, S.E, Cummins, D.M, Jacobsen, J.R, 1995. The morphologic basis for the extraction decision in Class II division 1 malocclusion: a comparative study. Am J Orthod and Dentofacial Orthop, 107, 129-135.

2. Carter, N.E,1987. Dentofacial changes in untreated Class II division 1 subjects. Br J Orthod, 14, 225-234.

3. Ingerval, B, Lennartsson, B, 1972. Facial skeletal morphology and dental arch dimensions in girls with postnorrmal occlusions (Angle Class II division 1). Odont Revy, 23, 63-78.
4. Singh G, 2004. Textbook of orthodontics. 2nd ed, New Delhi, Jaypee Brothers, 623.

5. Graber, T.M, Vanarsdall, I.R, 2000. Orthodontics current principles and techniques. 3rd ed, St Louis, Mosby,83.

6. Hoque, M.E,1995. Essentials of orthodontics for dental students. 3rd ed, Dhaka ,Apex, 2

7. Issacson,J.R, Zapel, J.R , Worms, W.F, Bevis, R.R, Speidel, T.M, 1977. Some effect of mandibular growth on the dental occlusion and the profile. Angle Orthodontist, 47(2),97-106.

8. Nanda, R,2004. Biomechanics and Esthetic Strategies in clinical orthodontics. Farmington, CT, 1.

9. Proffit, W.R, Fields, H.W, 2001. Contemporary Orthodontics. 4th ed. St Louis, Mosby, 422.

10. Bassigny, F, Bassigny, F, 1983. Manual of orthodontics \& dentofacial orthopedics. Paris, Masson, 111.

11. Allan, G, Brodie, 1971. Emerging concepts of facial growth. Angle Orthod, 41(2),103-118.

12. Hossain, M.Z, Hoque, M.E, Hoque, S,1994. Prevalence of malocclusion and treatment facilities at D.D.C \& H Bangladesh. Jr of Oral Health, 1, 4.

13. Bishara, S.E, Jacobsen, J.R, Angelakis, D,1996. Post treatment changes in male and female patients: A comparative study. Am J Orthod Dentofac Orthop, 110,624-626.

14. Ackerman and Proffit, 1969. The characteristics of malocclusion: A modern approach to classification and diagnosis. Am J Orthod, 50, $443-454$.

15. Papageorgieu, I.S, Papadopoulos, M.A, Zafiriadis, A,1998. Dentoalveolar characteristics in Class II division 2 malocclusion. Hel Orthod, 1,117.

16. Buschang, P.H, Stroud, J, Alexander, R.G, 1994. Differences in dental morphology among adult females with untreated Class I and Class II malocclusion. Eur J Orthod, 16,47-52.

17. Bishara, S.E, Bayati, P, Jacobsen, J.R,1996. Longitudinal comparisons of dental arch changes in normal and untreated Class II division 1 subjects and their clinical implications. Am J Orthod Dentofac Orthop, 110,483.

18. Ahmed, N, Chowdhury, K, 1996. Prevalence of malocclusion and its etiological factors. J of Oral Health, 2 (2), 12-16.

19. Akhter, F, 2006. Evaluation of different malocclusion and probable treatment based on IOTN (Index of Orthodontic Treatment Need) attending at Dhaka Dental College and Hospital. Thesis (FCPS), BCPS, Dhaka.

20. Rahman MM, 2007. Estimation of arch form, arch width and arch length in normal occlusion. Thesis (FCPS), BCPS, Dhaka.

Correspondence

Dr. Mohammed Monuwarul Islam BDS, FCPS

Dental Surgeon, Dhaka Dental College \& Hospital

Dhaka, Bangladesh.

E-mail: monuwarm@hotmail.com, Cell: 01711262870 